\title{
FORMULATION AND CHARACTERIZATION OF MUCOADHESIVE MATRIX TABLET OF NIZATIDINE
}

SARITADEVI GUPTA*, ASISH DEV

Deparment of Pharmaceutics, Oriental College of Pharmacy, Sanpada, Navi Mumbai, Maharastra, India. Email: sarita94g@gmail.com Received: 01 February 2018, Revised and Accepted: 13 March 2018

ABSTRACT

Objective: The objective of the work is to formulate nizatidine mucoadhesive matrix tablets which will significantly improve the bioavailability of drugs under the condition of prolonged use of drugs and reduce the total dosage of administered drug and reduce the side effect.

Method: Matrix tablet was prepared by direct compression of polymer such as HPMC K4M, carbopol-934p, and ethyl cellulose alone and in combination.

Result: After analysis of different evaluation parameter and drug release, F9 batch was selected as promising formulation for delivery of nizatidine as a mucoadhesive matrix tablet with $94.18 \%$ drug release at the $12^{\text {th }} \mathrm{h}$.

Conclusion: It was observed that the combination of both polymers in equal concentration gives the best drug release and sustains the drug release for $12 \mathrm{~h}$. Among the other batches, F9 batch was selected as an optimized batch because the pre- and post-compression parameter results are satisfactory.

Keywords: Nizatidine, Mucoadhesive matrix tablet, HPMC K4M, Carbopol-934p, Ethyl cellulose.

(C) 2018 The Authors. Published by Innovare Academic Sciences Pvt Ltd. This is an open access article under the CC BY license (http://creativecommons. org/licenses/by/4. 0/) DOI: http://dx.doi.org/10.22159/ajpcr.2018.v11i6.25063

\section{INTRODUCTION}

Oral route is the most convenient and the most commonly implemented route for drug delivery. Oral route of administration has been receiving more attention in pharmaceutical field because of the more flexibility in the designing of dosage form than drug delivery design for other routes. The oral drug delivery depends on various factors such as the type of delivery system, the disease being treated, and the patient, the length of the therapy, and the properties of the drug [1]. The controlled or sustain drug delivery attempts to sustain drug action at a predetermined rate by maintaining relatively constant and effective drug levels in the body with minimization of undesirable side effects. It also provides localized drug action by spatial placement of the sustained release system [2,3].

Nizatidine is a Class III drug, i.e. high-solubility, low-permeability compound [Fig. 1]. Nizatidine has short biological half-life (1-2 h) and susceptible to metabolism by colonic bacteria. It has been reported that the local delivery of H2-receptor antagonists increases the stomach wall receptor site bioavailability and increases efficacy of these drugs to reduce acid secretion [4].

Bioadhesion is an attachment of macromolecules that are synthetic or natural to mucus or the surface of the epithelium. This utilizes the bioadhesion property which adheres on hydration due to certain polymers and hence used for drug targeting at an exacting area for an extensive period of time in the body. When applied to mucosal epithelium, bioadhesive interactions occur primarily with the mucus layer and this phenomenon is referred to as mucoadhesion [5].

Matrix tablet formulations have been widely accepted oral controlled drug delivery formulations because of its simple nature, ease in the formulation process, highly reproducible, stability of the raw materials and dosage form, ease of scale-up, and process validation. The matrix system is the mixture of materials with the drug, which will cause the drug to slow down. However, this system has several subcategories: Hydrophobic matrices, lipid matrices, hydrophilic matrices, biodegradable matrices, and mineral matrices [6].
Advantages of bioadhesive drug delivery systems [7]

a. A prolonged residence time at the site of action or absorption,

b. A localization of the drug delivery system at a given target site,

c. An increase in the drug concentration gradient due to the intestine contact of the particles with the mucosal surface,

d. A direct contact with intestinal cells, which is the step earlier to particulate absorption.

\section{Nizatidine}

Chemical Name: dimethyl[(4-\{[(2-\{[1-(methylamino)-2-nitroethenyl $]$ amino\}ethyl)sulfanyl]methyl\}-1,3-thiazol-2-yl)methyl]amine.

\section{MATERIALS AND METHODS}

Nizatidine was a gift sample from Zhejiang Medicine \& Health Products Import \& Export Co., Ltd., China. HPMC K4M were procured from Chemdyes Corporation, Gujarat. Carbopol-934p were procured from Research-Lab Fine Chem Industries, Mumbai. Ethyl cellulose, microcrystalline cellulose, and magnesium stearate were procured from Thomas Baker Pvt. Ltd, Mumbai. All reagents used were of analytical grade.

\section{METHODS}

Drug excipient compatibility studies[8]

Fourier-transform infrared (FT-IR) spectrum matching approach was used for detection of any possible chemical interaction between nizatidine and polymers. IR spectroscopy was conducted using a FT-IR spectrophotometer (Jasco FT-IR 410), and the spectrum was recorded in the wavelength region of $4000-400 \mathrm{~cm}^{-1}$. The procedure consisted of dispersing a sample (drug alone or mixture of drug and excipients) in $\mathrm{KBr}$ and compressed into discs by applying a pressure of 5 tons for $5 \mathrm{~min}$ in a hydraulic press. The pellet was placed in the light path and the spectrum was obtained. Samples were prepared for nizatidine, polymers such as ethyl cellulose, carbopol-934, HPMC $\mathrm{K} 4 \mathrm{M}$, and physical mixture of drug with polymers. The spectra obtained were compared and interpreted for the functional group peaks. 


\section{PREFORMULATION STUDIES}

Ultraviolet (UV) spectrum of drug nizatidine

The solution of nizatidine in $0.1 \mathrm{~N} \mathrm{HCl}$ was screened in the range of $200-400 \mathrm{~nm}$.

\section{Melting point}

The melting point of drug was determined using packing a capillary method.

\section{Physical properties of drug powder}

The drug nizatidine undergoes through various tests to know its physical properties.

\section{Construction of calibration curve}

The calibration curve for nizatidine was determined in $0.1 \mathrm{~N} \mathrm{HCl} \mathrm{pH} 1.2$ in UV spectrophotometer. It is given in Fig. 2.

The flow properties of granules were characterized in terms of angle of repose, Carr's index, Compressibility index, and Hausner ratio. The bulk density and tapped density were determined, and from these data, Carr's index and Hausner ratio were calculated [9].

\section{Formulation of mucoadhesive matrix tablet of nizatidine}

Matrix tablet of nizatidine was prepared by direct compression method. The composition of formulations is shown in Table 2. All the powders were passed through a 40 mesh sieve. The batches were prepared by mixing the drug, polymer and diluents as given in Table 2 . The powder blend was lubricated with magnesium stearate and compressed using ( $9 \mathrm{~mm}$ diameter round, flat, and plain punches) multiple punch rotary tablet machine. In total, 10 formulations containing different amounts of HPMC K4M (F1, F2, F3), carbopol-934p (F4, F5, F6), and combination of HPMC K4M or carbopol-934p with ethyl cellulose (F7, F8, F9, F10) were prepared.

\section{CHARACTERIZATION OF MATRIX TABLETS}

\section{Thickness}

Five tablets were selected randomly from each batch and were used for thickness determination. The thickness of each tablet was measured in $\mathrm{mm}$ using a digital vernier caliper and their values were reported in millimeters. The mean and SD were calculated and reported.

\section{Weight variation test}

Ten tablets were selected randomly from each batch and individually weighed using an electronic balance. The average weight was calculated. The percentage deviation from average weight was reported.

Hardness
The strength of the tablet which prevents from chipping, abrasion or breakage under conditions of storage, transportation, and handling before usage depends on its hardness. The hardness of five tablets which randomly selected from each batch was measured using Monsanto hardness tester and expressed in $\mathrm{Kg} / \mathrm{cm}^{2}$. The average mean and SD were calculated.

\section{Friability}

Friability of tablets was performed using Roche friabilator. The tablets were carefully de-dusted before testing. Five tablets were randomly selected from each batch and accurately weighed. This tablet sample was placed in the drum. The drum was rotated 100 times, and the tablets were removed, re-weighed and percentage loss was determined.

\section{Drug content analysis}

Five tablets were weighed individually, and the average was calculated and grounded in a mortar with a pestle to get fine powder. An amount equivalent to $150 \mathrm{mg}$ of the drug was extracted with $100 \mathrm{ml}$ of $0.1 \mathrm{~N}$ $\mathrm{HCl}$. The drug content was determined by UV spectrophotometer at a wavelength $314 \mathrm{~nm}$, and the percentage drug content was calculated.

\section{Swelling index}

The swelling of mucoadhesive polymer is an important factor affecting adhesion. To carry out the study, a tablet was weighed and placed in a Petri dish containing $5 \mathrm{ml}$ of $0.1 \mathrm{~N} \mathrm{HCl}$ buffer $\mathrm{pH} 1.2$ in $10 \mathrm{~h}$ at regular interval of time $(1,2,3,4,5,6,7,8,9,10)$ and the tablet was taken care

Table 1: Physical properties of drug

\begin{tabular}{lll}
\hline Sr. No & Test & Result \\
\hline 1 & Bulk density $(\mathrm{g} / \mathrm{ml})$ & 0.443 \\
2 & Tap density $(\mathrm{g} / \mathrm{ml})$ & 0.564 \\
3 & Carr's compressibility & $22 \%$ \\
4 & Hausner ratio & 1.27 \\
5 & Angle of repose & $31^{\circ}$ \\
& Flow properties & Passable \\
\hline
\end{tabular}

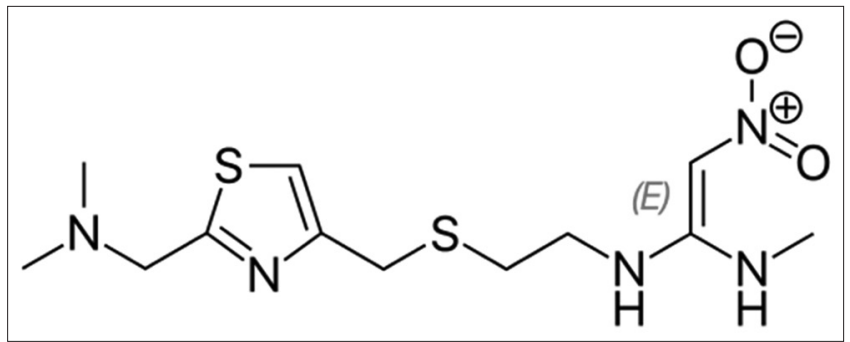

Fig. 1: Nizatidine drug structure

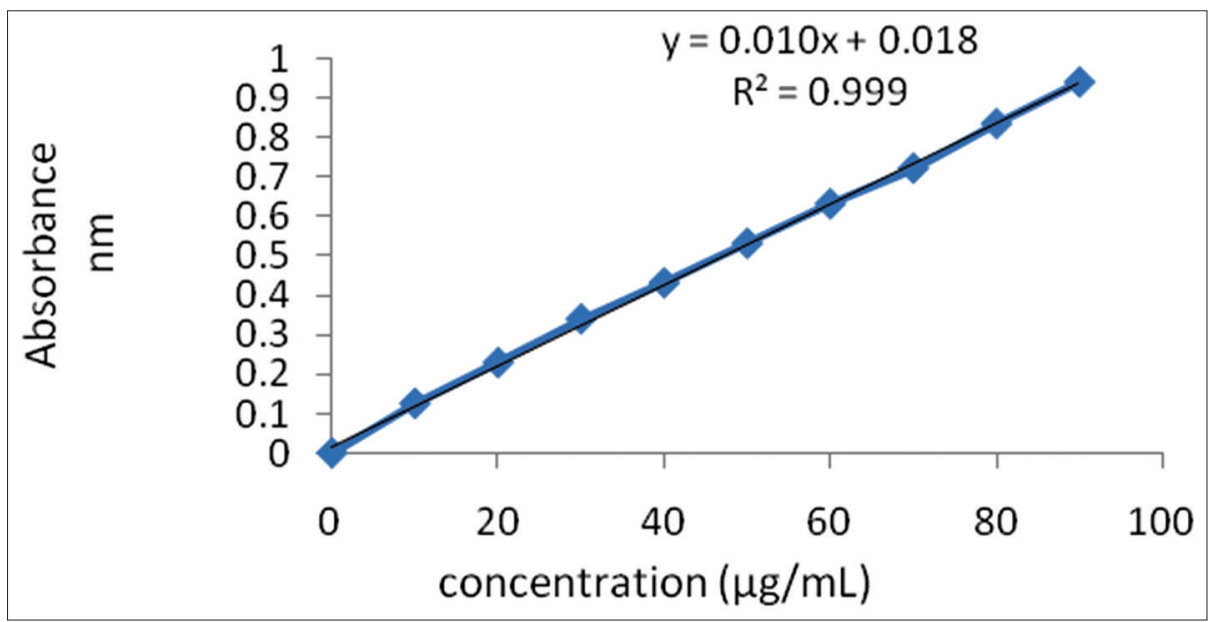

Fig. 2: Calibration curve of nizatidine 


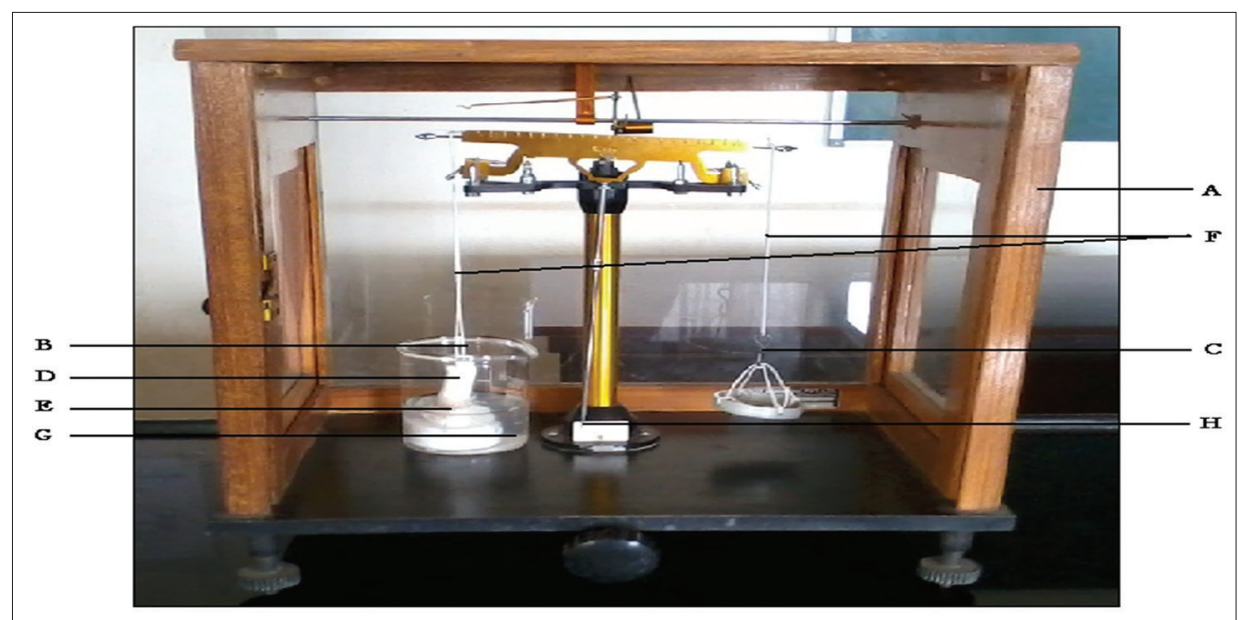

Fig. 3: In vitro bioadhesive strength measurement. (a) In vitro bioadhesive strength measurement modified balance apparatus, (b) left pan, (c) right pan, (d) teflon cylinder, (e) goat mucosa, (f) threads, (g) beaker containing solution, (h) pointer

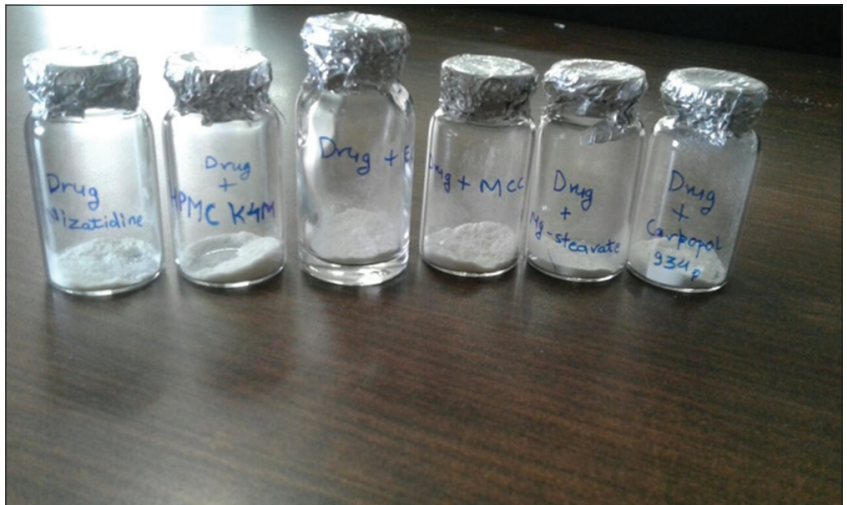

Fig. 4: Drug-excipient mixtures in vials

using filter paper. The swelling index was calculated using following formula,

Swelling index $=[($ Weight of swollen tablet - Initial weight of tablet $) /$ (Initial weight of tablet)] X 100

\section{Mucoadhesive strength measurement:[10-12]}

The mucoadhesive strength of the tablet was measured on the modified physical balance (Fig. 3). The apparatus consists of a modified double-beam physical balance in which the right and left pan has been replaced by lighter pans. The left side of the balance was made $5 \mathrm{~g}$ heavier than the right side by placing a $5 \mathrm{~g}$ weight on leftside pan. Another Teflon block of $3.8 \mathrm{~cm}$ diameter and $2 \mathrm{~cm}$ height was fabricated with an upward portion of $2 \mathrm{~cm}$ height and $1.5 \mathrm{~cm}$ diameter on one side. This was kept in a beaker, which was then placed below the left-hand set of the balance.

The goat gastric mucosa was used as the model membrane, and $\mathrm{pH} 1.2$ was used as the moistening fluid. The goat gastric mucosa was kept in Tyrode solution at $37^{\circ} \mathrm{C}$ for $2 \mathrm{~h}$. The underlying mucous membrane was separated and washed thoroughly with a $\mathrm{pH} 1.2$ solutions. It was then tied to Teflon-coated glass slide, and this slide was fixed over the protrusion in the Teflon block using a thread. The block was then kept in beaker containing $\mathrm{pH} 1.2$ buffer solutions at the level that just touches the membrane. By keeping a $5 \mathrm{~g}$ weight on the right pan, the two sides of the balance were made equal. The beaker with the Teflon block was kept below the left-hand setup of the balances. The tablets of each batch were struck on to the lower side of the left-hand side pan. The $5 \mathrm{~g}$ weight from the right pan was then removed. This lowered the left pan along with the tablet over the membrane with a weight of $5 \mathrm{~g}$. This was kept undisturbed for $5 \mathrm{~min}$. Then, the weight on the right-hand side was slowly added in an increment of $0.5 \mathrm{~g}$ till the tablet just separated from the membrane surface. The excess weight on the right pan, i.e., total weight minus $5 \mathrm{~g}$ was taken as a measure of the mucoadhesive strength.

From the mucoadhesive strength, the force of adhesion was calculated using the following formula:

Force of adhesion $(\mathrm{N})=\frac{\text { Bioadhesive strength }}{100} \times 9.81$

\section{In vitro drug release study}

In vitro drug release studies were performed using the USP dissolution apparatus Type II. The drug release profile was studied in $900 \mathrm{ml}$ of $0.1 \mathrm{~N} \mathrm{HCl}$ buffer of $\mathrm{pH} 1.2$ at $37 \pm 0.2^{\circ} \mathrm{C}$. The rotational speed of the paddle was $50 \mathrm{rpm}$. Aliquots of $5 \mathrm{ml}$ of dissolution medium were withdrawn at specific time intervals, filtered, and replaced with fresh medium. The samples were filtered through Whatman filter paper and analyzed after appropriate dilution by a UV spectrophotometer (Shimadzu UV 1800) at $314 \mathrm{~nm}$, and drug release was determined from the standard curve.

\section{Statistical analysis}

To evaluate contribution of each factor with different levels on responses, two-way analysis of variance (ANOVA) was performed using GraphPad Prism 7.04 software.

\section{RESULTS AND DISCUSSION}

\section{Drug excipient compatibility studies}

The results showed that the principle IR peak of pure drug and its physical mixture with polymer were almost similar, signifying no interaction between drug and polymer during formulation of tablets. Picture of vials having a drug excipient mixture is shown in Fig. 4.

\section{UV spectrum of drug nizatidine}

The solution of Nizatidine in $0.1 \mathrm{~N} \mathrm{HCl}$ was found to exhibit maximum absorption $(\lambda \max )$ at $314 \mathrm{~nm}$ after scanning in the range of 200$400 \mathrm{~nm}$. It is given in Fig. 5.

\section{Physical properties of drug powder}

Results of physical properties of drug powder are shown in Table 1.

The percent compressibility of the drug was $22 \%$ and angle of repose was $31^{\circ}$, suggesting that it can be directly compressed.

\section{Preformulation studies of powders}

The prepared powders were characterized for angle of repose, bulk density, tapped density, Hausner factor, Carr's index, and 
compressibility index, and the values were reported in Table 3. The angle of repose of the different batches of powders was determined as per method mentioned earlier, and the results ranged between $20.005^{\circ}$ and $24.38^{\circ}$. The powder with the angle of repose $<20^{\circ}$ indicates excellent flow properties. The bulk densities of powder were ranged between $0.300 \mathrm{~g} / \mathrm{cm}^{3}$ and $0.428 \mathrm{~g} / \mathrm{cm}^{3}$. The low bulk density is due to the presence of more fines in the powder. Tapped density ranged between $0.360 \mathrm{~g} / \mathrm{cm}^{3}$ and $0.521 \mathrm{~g} / \mathrm{cm}^{3}$.

\section{EVALUATION OF MATRIX TABLET}

Weight variation, thickness, hardness, friability, and drug content analysis

Results were represented in Table 4. The diameters of prepared tablets were ranged from 9.018 to 9.092 . The weights of prepared tablets were ranging from $277 \pm 13.89$ to $295.7 \pm 14$.78. The thickness of prepared tablets was ranged from 3.912 to 4.154 . It was also observed that increasing the polymer concentration resulted in slight decrease in the thickness of tablet formulations. These results indicate that the polymers may have highly binding properties. Hardness of tablet ranged from 4.834 to $9.5 \mathrm{~kg} / \mathrm{cm}^{2}$. For all formulation friability ranged from 0.0 to $0.8 \%$, it indicates that friability is within the prescribed limit of $1 \%$. The drug content $(\%)$ of matrix tablet from each formulation was found to be uniform and ranged from 94.19 to $97.41 \%$.

\section{Swelling studies}

Swelling index profile of all formulations is shown in Table 5. Swelling index of all formulations varies between 172.88 and $455.56 \%$. Swelling of the matrix tablet is indicated by the transition of the polymer from the glassy to the rubbery state. It is an important parameter in determining of the release characteristics of the matrix system. As swelling process proceeds, the gel layer gradually becomes thicker, and therefore, the drug concentration gradient along the diffusional path length is decreased results in the slow drug release.

\section{Measurement of bioadhesion force}

The mucoadhesive strength of the tablet was dependent on the property of the bioadhesive polymers, which on hydration adhere to the mucosal surface and also on the concentration of polymer used. Bioadhesive force values ranged from 1.86 to 4.8 . Results were represented in Table 6 and Fig. 7.

\section{In vitro dissolution studies}

All the ten formulations were subjected to in vitro dissolution studies using a USP Type II dissolution test apparatus. The dissolution medium $1.2 \mathrm{pH}$ buffer was used to study the drug release. The samples were withdrawn at different intervals of time and analyzed at $314 \mathrm{~nm}$ using a UV spectrophotometer. The cumulative percentage drug release was calculated. The data obtained from in vitro release for formulations prepared by direct compression technique are tabulated in Table 7 .

From the results, we can conclude that there was increase in the extend of duration of drug release with increase in concentration of polymer in the formula. From Fig. 8, it can be seen that formulations, i.e., F1, F2, and F3 containing 15\%, 20\%, and 25\% of HPMC K4M released more than $80 \%$ of the drug over $8 \mathrm{~h}$. No difference in release

Table 2: Composition of mucoadhesive matrix tablet of nizatidine prepared by direct compression

\begin{tabular}{|c|c|c|c|c|c|c|c|c|c|c|}
\hline Ingredients & F1 (mg) & F2 (mg) & F3 (mg) & F4 (mg) & F5 (mg) & F6 (mg) & F7 (mg) & F8 (mg) & F9 (mg) & F10 (mg) \\
\hline Nizatidine & 75 & 75 & 75 & 75 & 75 & 75 & 75 & 75 & 75 & 75 \\
\hline HPMC K4M & 45 & 60 & 75 & - & - & - & 37.5 & 30 & - & - \\
\hline Carbopol-934p & - & - & - & 45 & 60 & 75 & - & - & 37.5 & 30 \\
\hline Ethyl cellulose & - & - & - & - & - & - & 37.5 & 45 & 37.5 & 45 \\
\hline Microcrystalline cellulose & 176 & 161 & 146 & 176 & 161 & 146 & 146 & 146 & 146 & 146 \\
\hline Magnesium stearate & 4 & 4 & 4 & 4 & 4 & 4 & 4 & 4 & 4 & 4 \\
\hline Total (mg) & 300 & 300 & 300 & 300 & 300 & 300 & 300 & 300 & 300 & 300 \\
\hline
\end{tabular}

Table 3: Physical properties of nizatidine blend with different excipient

\begin{tabular}{|c|c|c|c|c|c|c|}
\hline $\begin{array}{l}\text { Formulation } \\
\text { code }\end{array}$ & $\begin{array}{l}\text { Bulk density } \\
(\mathrm{g} / \mathrm{ml})\end{array}$ & $\begin{array}{l}\text { Tapped density } \\
(\mathrm{g} / \mathrm{ml})\end{array}$ & $\begin{array}{l}\text { Angle of } \\
\text { repose (degree) }\end{array}$ & $\begin{array}{l}\text { Compressibility } \\
\text { index }(\%)\end{array}$ & $\begin{array}{l}\text { Carr's } \\
\text { index (\%) }\end{array}$ & $\begin{array}{l}\text { Hausner } \\
\text { ratio }\end{array}$ \\
\hline $\mathrm{F} 1$ & 0.353 & 0.462 & 23.88 & 23.52 & 21.90 & 1.30 \\
\hline F2 & 0.428 & 0.521 & 22.24 & 17.80 & 18 & 1.217 \\
\hline F3 & 0.352 & 0.445 & 24.38 & 20.58 & 20.9 & 1.264 \\
\hline $\mathrm{F} 4$ & 0.300 & 0.400 & 21.75 & 25 & 25 & 1.33 \\
\hline F5 & 0.300 & 0.375 & 21.44 & 20 & 20 & 1.25 \\
\hline F6 & 0.300 & 0.360 & 22.04 & 17.5 & 17 & 1.20 \\
\hline F8 & 0.363 & 0.428 & 23.85 & 15.15 & 16 & 1.179 \\
\hline F9 & 0.333 & 0.413 & 21.55 & 19.44 & 20 & 1.24 \\
\hline F10 & 0.352 & 0.413 & 21.31 & 14.70 & 15 & 1.17 \\
\hline
\end{tabular}

Table 4: Post-compression parameters of mucoadhesive matrix tablets of nizatidine

\begin{tabular}{|c|c|c|c|c|c|c|}
\hline $\begin{array}{l}\text { Formulation } \\
\text { code }\end{array}$ & Diameter* (mm) & Thickness* (mm) & Hardness* $\left(\mathrm{kg} / \mathrm{cm}^{2}\right)$ & Friability (\%) & $\%$ Weight variation ${ }^{\wedge}$ & $\%$ drug content ${ }^{\#}$ \\
\hline F1 & $9.046 \pm 0.011$ & $4.154 \pm 0.009$ & $4.834 \pm 0.289$ & 0.7 & $289 \pm 7.397$ & $95.07 \pm 0.375$ \\
\hline $\mathrm{F} 2$ & $9.092 \pm 0.013$ & $4.14 \pm 0.07$ & $5.5 \pm 0.00$ & 0.7 & $280 \pm 9.428$ & $96.77 \pm 0.416$ \\
\hline F3 & $9.068 \pm 0.008$ & $4.12 \pm 0.020$ & $5.834 \pm 0.289$ & 0.7 & $295.7 \pm 4.347$ & $93.99 \pm 0.00$ \\
\hline $\mathrm{F} 4$ & $9.06 \pm 0.016$ & $3.974 \pm 0.013$ & $6.34 \pm 0.289$ & 0.7 & $292.4 \pm 4.164$ & $94.86 \pm 0.375$ \\
\hline F5 & $9.04 \pm 0.010$ & $3.926 \pm 0.011$ & $7.67 \pm 0.289$ & 0 & $295 \pm 4.346$ & $96.76 \pm 0.393$ \\
\hline F6 & $9.04 \pm 0.012$ & $3.912 \pm 0.008$ & $8.34 \pm 0.289$ & 0.8 & $295.6 \pm 4.274$ & $96.56 \pm 0.640$ \\
\hline F8 & $9.032 \pm 0.013$ & $4.018 \pm 0.008$ & $8.5 \pm 0.00$ & 0.7 & $283.6 \pm 4.575$ & $96.98 \pm 0.393$ \\
\hline F9 & $9.018 \pm 0.008$ & $4.026 \pm 0.015$ & $9 \pm 0.00$ & 0 & $277.8 \pm 3.938$ & $96.56 \pm 0.640$ \\
\hline F10 & $9.028 \pm 0.008$ & $4.016 \pm 0.005$ & $9.5 \pm 0.00$ & 0 & $279.1 \pm 6.385$ & $94.21 \pm 0.375$ \\
\hline
\end{tabular}

*All values expressed in mean $\pm S D, n=5$. ^All value expressed in mean $\pm S D, n=10$. *All value expressed in mean $\pm S D, n=3$. SD: Standard deviation 
rate was observed between tablets containing either $15 \%$ and $20 \%$ of HPMC K4M. Drug release decreased significantly in the formulation containing $25 \%$ of HPMC K4M. It can be seen that formulations, i.e., F4, F5, and F6 (Fig. 9) loaded with 15\%, 20\%, and $25 \%$ of the carbopol-934P released over $90 \%$ of the drug over $4 \mathrm{~h}, 6 \mathrm{~h}$, and $6 \mathrm{~h}$, respectively. Tablets containing $25 \%$ of carbopol-934p were able to form the gelatinous layer around the tablet core, and the drug release was found to be $95.55 \%$ within $6 \mathrm{~h}$ of dissolution study. Therefore, in order to control the initial burst release, ethyl cellulose was included in the matrix of the next batch of tablets in the ratio of $1: 1$ along with HPMC K4M (F7) or carbopol-934p (F9) which resulted in extending the drug release for a period of $12 \mathrm{~h}$ indicating fair uniform drug release throughout the dissolution period. This may be due to a more rigid, complex structure formed by hydrophilic polymers (HPMC K4M and carbopol-934p) in the presence of ethyl cellulose, which helped in retaining the drug in the matrix and hindering rapid diffusion of soluble drug from the matrix. Increasing the concentration of ethyl cellulose shows more retardation in the release of the drug from the formulations, i.e., F8 and F10 containing ethyl cellulose in combination with HPMC K4M and carbopol-934p in the ratio 1:1.5, respectively. F8 showed $56.13 \%$ and F10 showed only $60.35 \%$ of drug release in $12 \mathrm{~h}$ of dissolution study, which may result in therapeutic failure of the formulation. As shown in Fig. 10 and Fig. 11.

\section{CONCLUSION}

In the present work, an attempt has been made formulating mucoadhesive matrix tablets of nizatidine using various hydrophilic polymers such as HPMC K15M, carbopol-934P, and hydrophobic

Table 5: Swelling index study of all formulations

\begin{tabular}{|c|c|c|c|c|c|c|c|c|c|c|}
\hline Time & $\%$ F1 & $\%$ F2 & $\%$ F3 & $\%$ F4 & $\%$ F5 & $\%$ F6 & $\%$ F7 & $\%$ F8 & $\%$ F9 & $\%$ F10 \\
\hline 0 & 0 & 0 & 0 & 0 & 0 & 0 & 0 & 0 & 0 & 0 \\
\hline 1 & 87.29 & 85.23 & 78.08 & 146.18 & 115.57 & 112.07 & 104.41 & 93.22 & 104.73 & 110.88 \\
\hline 2 & 111.71 & 114.77 & 114.04 & 146.18 & 142.91 & 141.03 & 128.14 & 102.71 & 130.41 & 126.67 \\
\hline 3 & 122.74 & 132.55 & 120.89 & 177.08 & 159.52 & 147.59 & 138.98 & 106.78 & 138.51 & 144.91 \\
\hline 4 & 164.88 & 164.43 & 156.85 & 189.93 & 176.12 & 156.55 & 152.88 & 116.61 & 151.69 & 145.96 \\
\hline 5 & 170.90 & 173.49 & 173.29 & 214.24 & 197.58 & 178.97 & 169.83 & 123.05 & 166.22 & 155.44 \\
\hline 6 & 211.04 & 209.06 & 188.36 & 245.83 & 242.56 & 229.66 & 173.90 & 133.22 & 171.96 & 166.67 \\
\hline 8 & 231.10 & 234.23 & 215.75 & 316.67 & 302.08 & 279.31 & 204.41 & 157.63 & 195.95 & 180.35 \\
\hline 9 & 236.12 & 235.91 & 239.38 & 425.35 & 350.17 & 292.07 & 215.25 & 170.85 & 203.72 & 182.46 \\
\hline 10 & 265.22 & 244.97 & 242.81 & 455.56 & 363.32 & 338.97 & 220.34 & 172.88 & 204.73 & 190.88 \\
\hline
\end{tabular}

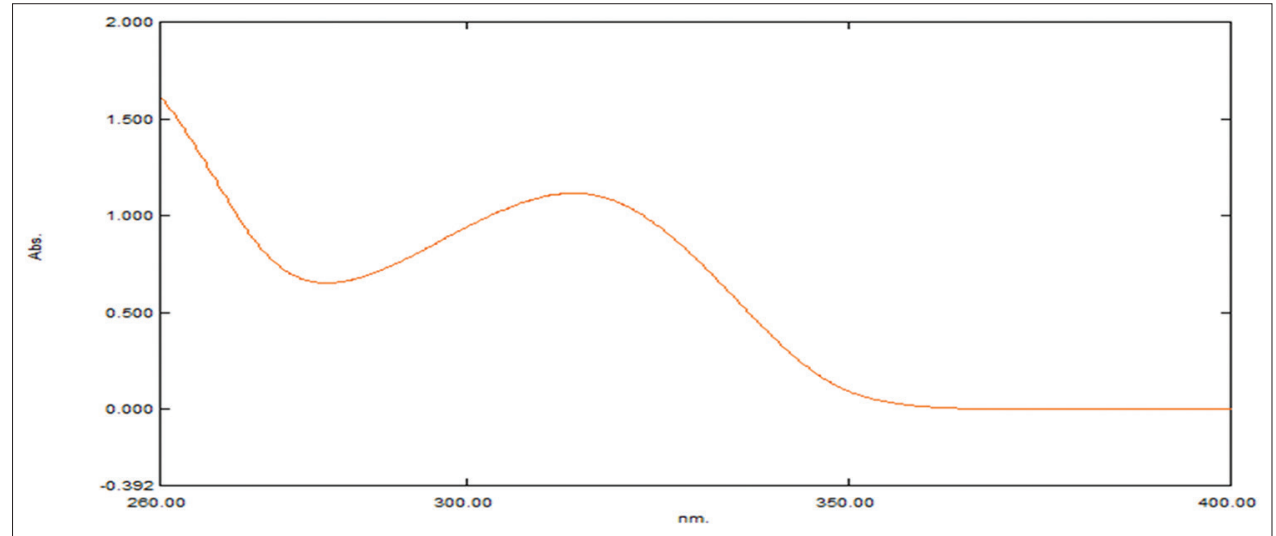

Fig. 5: Ultraviolet spectrum of nizatidine

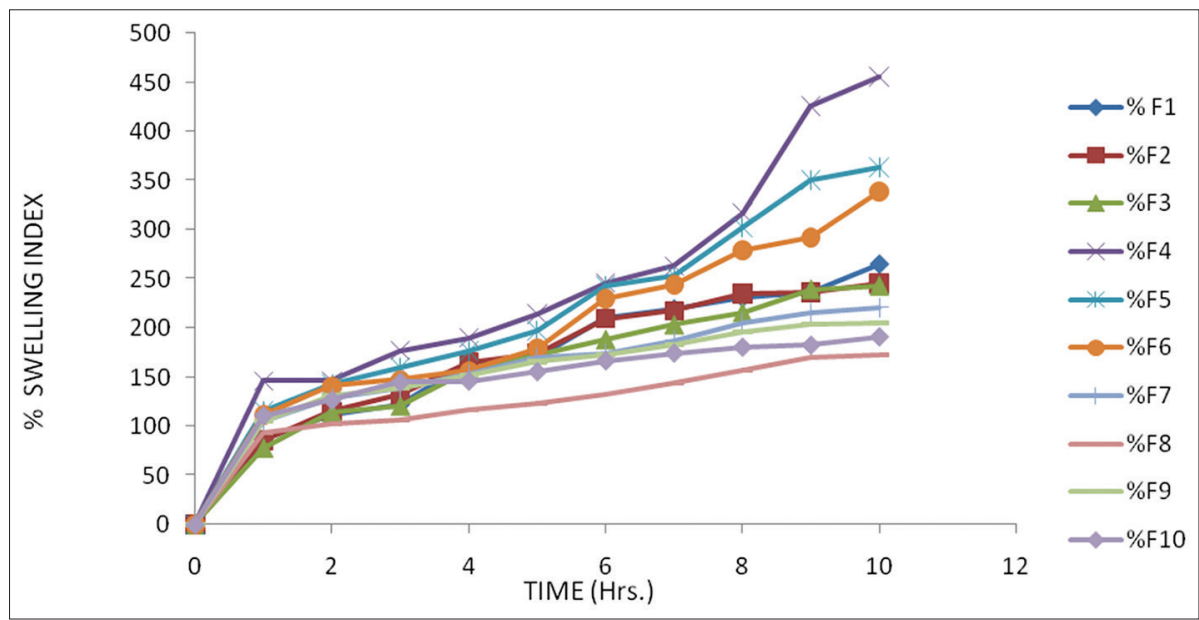

Fig. 6: Swelling index of all formulations (F1-F10) 
polymers such as ethyl cellulose. Mucoadhesive matrix tablet of nizatidine was prepared by direct compression method. In vitro dissolution studies of ten batches concluded that the batch F1, F2, and F3 tablets completely disintegrated at $8 \mathrm{~h}$ and batch F4, F5, and F6 completely disintegrated at 4, 6, and $6 \mathrm{~h}$, respectively, so these batches were rejected. Among the other batches, F9 batch

Table 6: Bioadhesive force of all formulations

\begin{tabular}{lll}
\hline fBatch no. & Bioadhesive strength $(g)$ & Bioadhesion force $(\mathbf{N})$ \\
\hline F1 & 25 & 2.45 \\
F2 & 34 & 3.33 \\
F3 & 39 & 3.82 \\
F4 & 19 & 1.86 \\
F5 & 27 & 2.64 \\
F6 & 34 & 3.33 \\
F7 & 40 & 3.92 \\
F8 & 44 & 4.31 \\
F9 & 47 & 4.61 \\
F10 & 49 & 4.8 \\
\hline
\end{tabular}

was selected as an optimized batch because the pre- and postcompression parameter results are satisfactory. The F9 batch showed best result as the percent cumulative drug release of F9 is $94.18 \%$ at $12 \mathrm{~h}$, and also, the \% swelling index is about $204.73 \%$ at $10 \mathrm{~h}$. The tablet does not swell too much, which results in controlled release of the drug and also shows good bioadhesive strength in acidic media.

\section{ACKNOWLEDGMENTS}

We are thankful to Zhejiang Medicine \& Health Products Import \& Export Co., Ltd., China, for providing us gift samples of the drug. The authors are thankful to Prof. (Dr.) Mrs. Sudha Rathod, Principal of Oriental College of Pharmacy, Sanpada, Navi Mumbai, India, for providing all the facilities for this research project. We are also thankful to Mr. S.K. Kar (Asst. Prof.) for helping in the process of procurement of the API.

\section{CONFLICTS OF INTERESTS}

The authors declare that there is no conflict of interests regarding the publication of this paper

Table 7: In vitro drug release of all formulations (\% cumulative release)

\begin{tabular}{|c|c|c|c|c|c|c|c|c|c|c|}
\hline Time & F1 & F2 & F3 & F4 & F5 & F6 & F7 & F8 & F9 & F10 \\
\hline 0 & 0 & 0 & 0 & 0 & 0 & 0 & 0 & 0 & 0 & 0 \\
\hline 0.5 & 14.28 & 11.92 & 1.33 & 21.33 & 21.33 & 15.45 & 0.16 & -1.02 & 0.16 & -1.02 \\
\hline 1 & 35.53 & 31.99 & 4.87 & 33.22 & 33.22 & 27.30 & 1.33 & 1.33 & 1.33 & 0.15 \\
\hline 2 & 44.17 & 38.23 & 33.25 & 45.17 & 45.17 & 45.10 & 4.87 & 3.69 & 6.05 & 2.51 \\
\hline 3 & 50.31 & 39.62 & 45.20 & 68.94 & 57.18 & 63.00 & 8.43 & 8.41 & 8.43 & 7.23 \\
\hline 4 & 51.76 & 45.72 & 63.40 & 95.21 & 71.61 & 79.81 & 12.00 & 15.52 & 20.25 & 9.61 \\
\hline 6 & 69.68 & 75.38 & 77.86 & - & 94.36 & 95.55 & 27.36 & 20.31 & 29.77 & 20.21 \\
\hline 10 & - & - & - & - & - & - & 63.05 & 44.12 & 74.94 & 35.60 \\
\hline 12 & - & - & - & - & - & - & 83.40 & 56.13 & 94.18 & 60.35 \\
\hline
\end{tabular}

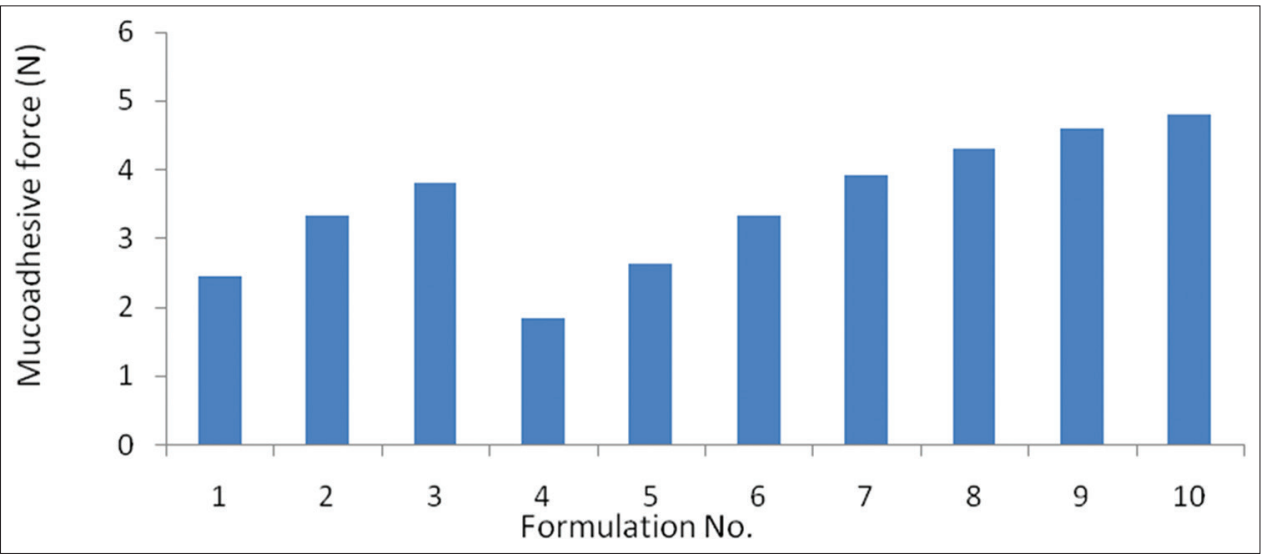

Fig. 7: Mucoadhesive test for all formulations (F1-10)

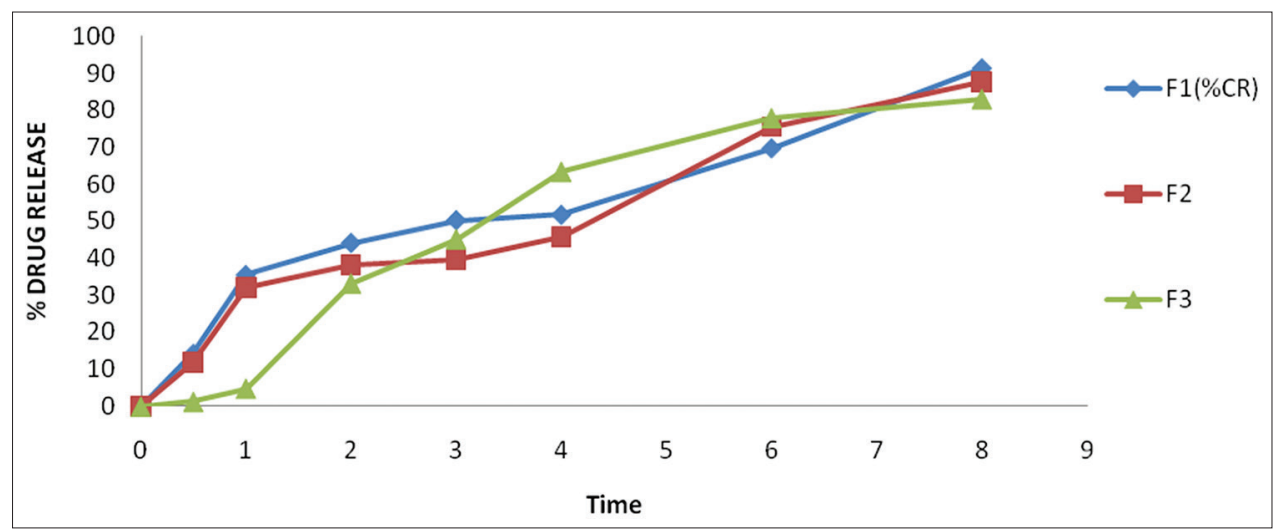

Fig. 8: In vitro drug release profile of nizatidine tablets made from HPMC K4M polymer 


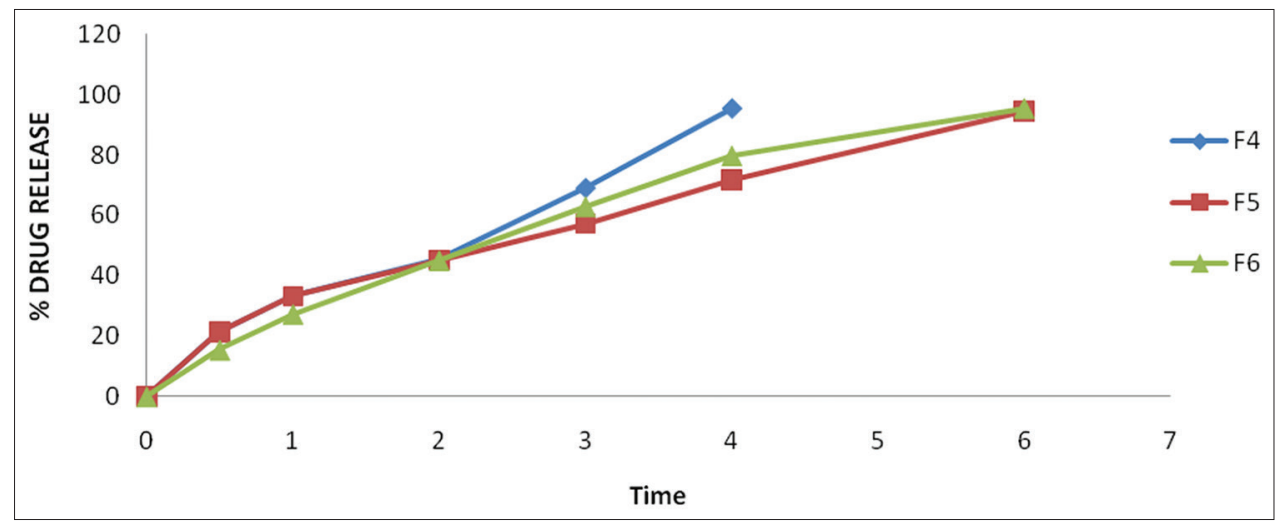

Fig. 9: In vitro drug release profile of nizatidine tablets made from carbopol-934p polymer

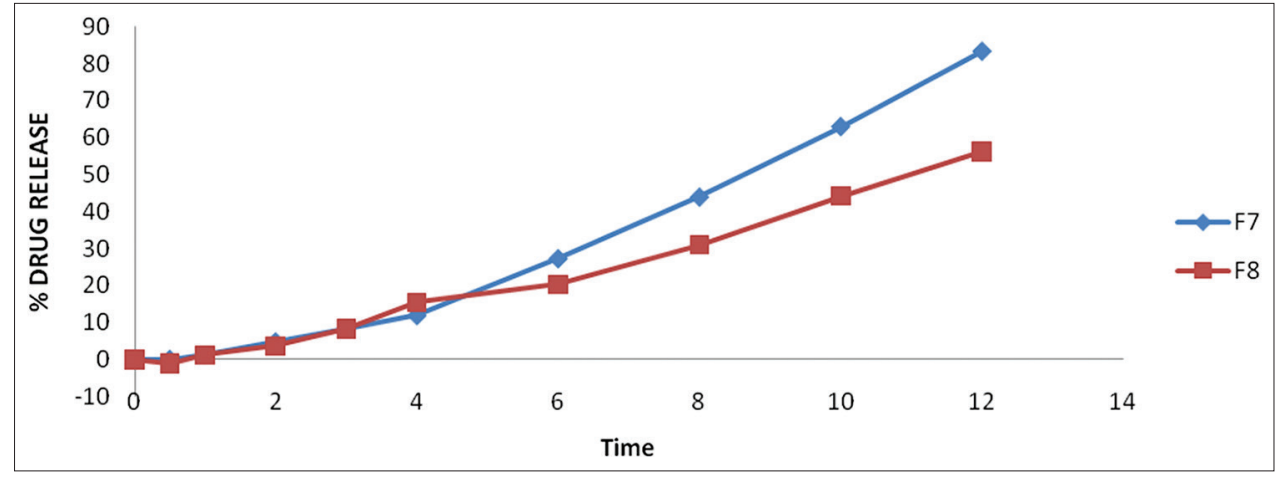

Fig. 10: In vitro drug release profile of nizatidine tablets made from HPMC K4M and ethyl cellulose polymer

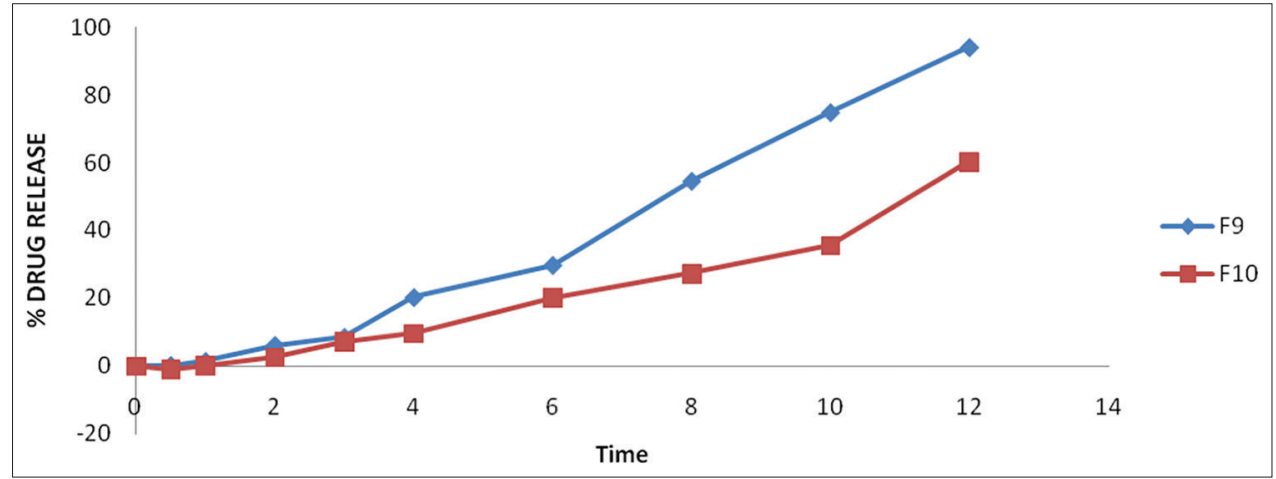

Fig. 11: In vitro drug release profile of nizatidine tablets made from carbopol-934p and ethyl cellulose polymer

\section{AUTHOR'S CONTRIBUTION}

We declare that this work was done by the authors named in this article and all liabilities pertaining to claims relating to the content of this article will be borne by the authors. Ms. Saritadevi Gupta collected the data, analyzed the data, all the laboratory work performed, and wrote the introduction, discussion, and the material and method part. Mr. Asish Dev proofreads the whole manuscript as well as helps in designing and conducting the study.

\section{REFERENCES}

1. Vyas SP, Khar RK, Bioadhesive and Mucoadhesive System, Controlled Drug Delivery System. $2^{\text {nd }}$ ed. New Delhi: Vallabh Prakashan; 2012. p. $6,156,258-98$.

2. Robinson JR, Lee VH, Controlled Drug Delivery: Fundamentals and Applications. $2^{\text {nd }}$ ed. New York: Marcel Dekker Inc., Taylor and Francis; 1987. p. 20, 3-49.

3. Brahmankar DM, Jaiswal SB, Controlled Release Medication, Biopharmaceutics and Pharmacokinetics. $2^{\text {nd }}$ ed. Nagpur: VallabhPrakashan; 2009. p. 397-9.

4. Balata G, et al. Design and evaluation of gastroretentive floating tablet of nizatidine: A trial to improve its efficacy. Int J Pharm Pharm Sci 2014;6:423-9.

5. Mathiowitz E, Chickering DE, Lehr CM. Defination Mechanism and Theories of Bioadhesion, Bioadhesive Drug Delivery Systems. USA: Marcel Dekker, Eastern Hemisphere Dustribution; 2010. p. 98, 1-22.

6. Gupta S, Dev A, Mansoori S, Yelwe A. Role of matrix tablet in sustained release system. World J Pharm Res 2017;6:1705-24

7. Pathan A, Dev A, Formulation and evaluation of bioadhesion drug delivery system. Pharm Biol Eval 2016;3:377-87.

8. Shaikh AC, Nizam S, Siraj S, Khan T, Patel MS, Zameeruddin M, et al. Formulation and evaluation of sustained release tablets of aceclofenac using hydrophilic matrix system. Int J Pharm Pharm Sci 2011;3:145-8.

9. Charyulu NR, Patel K, Jose J. Formulation and evaluation of acyclovir matrix tablet using mucoadhesive polymer. J Drug Deliv Ther 2013;3:52-7.

10. Singh S, Govind M, Bothara SB. A Review on in vitro-in vivo mucoadhesive strength assessment. Pharma Tech Medica 2013;2:221-7.

11. Tangri P, Madhav NV. Oral mucoadhesive drug delivery systems: A Review. Int J Biopharm 2011;2:36-46.

12. Khurana S, Madhav NV, Pranshu T. Mucoadhesive drug delivery: Mechanism and method of evaluation: A Review. Int J Pharm Biosci 2011;2:458-64. 